\title{
Perbedaan Pemberian ASI Eksklusif Antara Ibu Rumah Tangga dengan Ibu yang Bekerja di Luar Rumah di BPS Umu Hani Bantul Tahun 2011
}

\author{
Dyah Kartika Sari ${ }^{1}$, Prasetya Lestari ${ }^{2}$, Nining Sulistyawati ${ }^{3}$ \\ 1, 2, 3 Sekolah Tinggi IImu Kesehatan Alma Ata Yogyakarta \\ Jalan Ringroad Barat Daya No 1 Tamantirto, Kasihan, Bantul Yogyakarta
}

\begin{abstract}
Abstrak
Berdasarkan data dari World Health Organization (WHO), 54\% penyebab kematian bayi di dunia dipengaruhi oleh faktor gizi yang didalamnya juga dipengaruhi oleh pemberian ASI (Air Susu Ibu). Saat ini terjadi kecenderungan penurunan pemanfaatan ASI pada sebagian masyarakat. Hal ini disebabkan oleh pergeseran paradigma dalam setiap wanita dan meningkatnya pemahaman kaum wanita tentang aktualisasi diri. Tujuan penelitian untuk mengetahui perbedaan pemberian ASI eksklusif antara ibu rumah tangga dengan ibu yang bekerja di luar rumah di BPS Umu Hani Bantul. Jenis penelitian observasional dengan rancangan cross-sectional, subyek penelitian adalah dengan menggunakan teknik consecutive sampling. Data didapat dengan menggunakan kuisioner dan dianalisa melalui tabel distribusi frekuensi subyek, uji statistik dengan menggunakan chi-square. Hasil didapat sebanyak $84 \%$ ibu menyusui di BPS Umu Hani menjadi ibu rumah tangga, 15,9\% ibu menyusui di BPS Umu Hani bekerja di luar rumah dan sebanyak 68,2\% ibu menyusui di BPS Umu Hani memberikan ASInya secara Eksklusif. Penelitian ini menunjukkan adanya perbedaan yang signifikan proporsi pemberian ASI eksklusif pada ibu rumah tangga dan ibu yang bekerja di luar rumah dan dari hasil statistik $p<0,05$, hipotesis diterima.
\end{abstract}

Kata Kunci : ASI Eksklusif, Pekerjaan Ibu.

\section{Comparison of Provision Exclusive Brestfeeding between Household and Worker Mothers at BPS Umu Hani Bantu 2011}

\begin{abstract}
Based on World Health Organization (WHO), The cause of $54 \%$ mortality baby in the world is influenced by nitrition factors including affected by granting breast-feeding. Tendency of the use breast feeding in some society is declining. This is due to paradigm shifting in any women because of growing understanding women about self-actualisazion.

This research aims to compare providion of exclusive breastfeeding between working mothers and household mothers at BPS Umu Hani Bantul. This observational study used cross-sectional design with consecutive sampling. Data were obtained by using questionnaire and analysed through table a frequency distribution subjects and data statistic was tested by using chi-square. The result were $84 \%$ breastfeeding mothers at BPS Umu Hani as housewife, $15.9 \%$ of those working outside and at about $68,2 \%$ given exclusive breastfeeding. There was significantly distinctive at about $p<0,05$ on the proportion of exclusive breast-feeding given by household mothers and housewife mothers.
\end{abstract}

Keywords: Exclusive, Breast-Fed A Mother.

Info Artikel:

Artikel dikirim pada 11 November 2013

Artikel diterima pada 12 November 2013 


\section{Pendahuluan}

Kesalahan prosedur pemberian ASI dan kurang tepatnya pemberian makanan tambahan pada bayi menyebabkan Angka Kematian Bayi (AKB) cukup tinggi. Cakupan jumlah bayi yang diberi ASI eksklusif provinsi Daerah Istimewa Yogyakarta pada tahun 2009 adalah 35,28\% (12.608), sedangkan jumlah dari bayi di propinsi Daerah Istimewa Yogyakarta secara keseluruhan yaitu 35.736 bayi dari lima kabupaten atau kota seperti ; kabupaten Kulon Progo yang benar-benar ASI eksklusif yaitu 50,66 \%, Kabupaten Gunung Kidul 26,41 \%,Kabupaten Sleman 45,52 $\%$, Kotamadya Yogyakarta 30,91\%, dan terakhir Kabupaten Bantul 25,21\% yang merupakan kabupaten yang cakupan ASI eksklusifnya paling rendah ${ }^{1}$

BPS Ummu Hani merupakan salah satu BPS di Kabupaten Bantul yang masyarakatnya mayoritas bermata pencaharian sebagai pengrajin termasuk ibu rumah tangga juga bekerja, dan di studi pendahuluan yang dilakukan pada hari Minggu tanggal 13 Februari 2011 didapatkan ibu-ibu melakukan imunisasi di BPS tersebut, ada sejumlah 95 bayi yang usianya sudah 6-12 bulan, dan diambil sample 10 bayi.Yang diberikan ASI eksklusif yaitu ada 3 bayi dan 7 bayi yang tidak ASI eksklusif.

\section{Bahan dan Metode}

Jenis penelitian Observasional dengan pendekatan cross-sectional. Sampel yang digunakan Consecutive sampling yang berjumlah 44 sampel di BPS Umu Hani Bantul Yogyakarta. Penelitian menggunakan instrument berupa kuesioner dengan didukung data primer.

\section{Hasil dan Pembahasan}

Tabel 1. Distribusi Frekuensi Karakteristik Responden Berdasarkan Kelompok Umur

\begin{tabular}{ccc}
\hline $\begin{array}{c}\text { Kelompok Umur } \\
\text { (Tahun) }\end{array}$ & Frekuensi & Prosentase (\%) \\
\hline$<20$ & 4 & 9,1 \\
$20-24$ & 11 & 25,0 \\
$25-29$ & 14 & 31,8 \\
$30-34$ & 14 & 31,8 \\
$35-39$ & 1 & 2,3 \\
\hline Jumlah & 44 & 100 \\
\hline
\end{tabular}

Sumber : Data Primer 2011

Pada Tabel 1. menunjukkan bahwa responden yang paling banyak adalah yang berumur 25-29 tahun dan 30-34 tahun dengan masing-masing berjumlah 14 orang $(31,8 \%)$. Sedangkan kelompok umur 35-39 tahun merupakan yang paling sedikit dengan jumlah responden sebanyak 1 orang $(2,3 \%)$.

Tabel 2. Distribusi frekuensi karakteristik responden berdasarkan Pendidikan di BPS UmuHani Bantul 2011

\begin{tabular}{ccc}
\hline Pendidikan & Frekuensi & Prosentase (\%) \\
\hline SD & 11 & 25,0 \\
SMP & 11 & 25,0 \\
SMA & 19 & 43,2 \\
PT & 3 & 6,8 \\
\hline Jumlah & 44 & 100 \\
\hline
\end{tabular}

Sumber : Data Primer 2011

Pada Tabel 2 menggambarkan tingkat pendidikan pada responden. Didapatkan bahwa lebih banyak responden berpendidikan SMA yaitu sebanyak 19 orang (43,2\%). Sedangkan yang paling sedikit adalah Perguruan Tinggi (PT) sebanyak 3 orang $(6,8 \%)$. Pekerjaan responden dikelompokkan menjadi dua yaitu menjadi ibu rumah tangga (IRT) dan yang mempunyai pekerjaan diluar rumah.

Tabel 3. Distribusi Frekuensi Karakteristik Responden Berdasarkan Pekerjaan Ibu Menyusui DiBPS Umu Hani Bantul 2011

\begin{tabular}{lcc}
\hline \multicolumn{1}{c}{ Pekerjaan } & Frekuensi & Prosentase (\%) \\
\hline IRT & 37 & 84,1 \\
Bekerja & 7 & 15,9 \\
\hline Jumlah & 44 & 100 \\
\hline
\end{tabular}

Sumber : Data Primer 2011

Pada Tabel 3. menunjukkan bahwa sebagian besar responden menjadi ibu rumah tangga (IRT) yaitu sebanyak 37 orang $(84,1 \%)$. Sedangkan yang bekerja diluar rumah hanya 7 orang $(15,9 \%)$.

Tabel 4. Distribusi Frekuensi Pemberian ASI Eksklusif Pada Ibu Menyusui Di BPS Umu Hani Bantul 2011

\begin{tabular}{lcc}
\hline \multicolumn{1}{c}{ ASI Eksklusif } & Frekuensi & Prosentase (\%) \\
\hline Ya & 30 & 68,2 \\
Tidak & 14 & 31,8 \\
\hline Jumlah & 44 & 100 \\
\hline
\end{tabular}

Sumber : Data Primer 2011

Pada Tabel 4. menunjukkan bahwa lebih banyak responden yang memberikan ASI Eksklusif yaitu sebanyak 30 orang $(68,2 \%)$ dan yang paling sedikit adalah responden yang tidak memberikan ASI ekskluif yaitu sebanyak 14 orang $(31,8 \%)$.

Pada Tabel 5. menunjukkan bahwa responden yang bekerja sebagai ibu rumah tangga sebanyak 37 orang. Dari jumlah tersebut yang memberikan ASI secara eksklusif sebanyak 28 orang $(75,7 \%)$ dan 9 
Tabel 5. Tabulasi Silang dan Uji Chi Square Perbedaan pemberian ASI eksklusif antara ibu rumah tangga (IRT) dan yang bekerja diuar rumah di BPS Umu Hani 2011

\begin{tabular}{|c|c|c|c|c|c|c|c|c|}
\hline \multirow[t]{3}{*}{ Pekerjaan } & \multicolumn{4}{|c|}{ ASI Eksklusif } & \multirow{2}{*}{\multicolumn{2}{|c|}{ Total }} & \multirow[t]{2}{*}{$x^{2}$} & \multirow{2}{*}{$\begin{array}{c}P \\
\text { Value }\end{array}$} \\
\hline & \multicolumn{2}{|c|}{$\mathrm{Ya}$} & \multicolumn{2}{|c|}{ Tidak } & & & & \\
\hline & $f$ & $\%$ & $f$ & $\%$ & $f$ & $\%$ & 6,02 & 0,014 \\
\hline IRT & 28 & 75,7 & 9 & 24,3 & 16 & 100 & & \\
\hline Bekerja & 2 & 28,6 & 5 & 71,4 & 12 & 100 & & \\
\hline Jumlah & 30 & 68,2 & 14 & 31,8 & 44 & 100 & & \\
\hline
\end{tabular}

Sumber: Data primer 2011

orang (24,3\%) yang lainnya tidak memberikan ASI secara eksklusif.Sedangkan jumlah ibu menyusui yang bekerja diluar rumah sebanyak 7 orang. Dari jumlah tersebut yang memberikan ASI secara eksklusif hanya 2 orang $(28,2 \%)$ dan 5 orang $(71,4 \%)$ tidak memberikan ASI secara eksklusif. Dengan demikian proporsi pemberian ASI eksklusiflebih besar pada ibu rumah tangga dibandingkan pada ibu yang bekerja. Hasil perhitungan statistik menggunakan uji chi square diperoleh $p$-value sebesar 0,014 $(p<0,05)$. Hal ini dapat disimpulkan bahwa ada perbedaan yang signifikan pemberian ASI eksklusif antara ibu rumah tangga dan yang bekerja diluar rumah di BPS Umu Hani Bantul 2011.

Hasil analisis univariat menunjukkan bahwa sebagian besar ibu menyusui tidak bekerja atau hanya sebagai ibu rumah tangga yaitu sebanyak 37 orang $(84,1 \%)$. Sedangkan yang bekerja sebanyak 7 orang $(15,9 \%)$ yaitu sebagai pengrajin dan berdagang. Lokasi BPS Umu Hani berdekatan dengan wilayah pengrajin sehingga mayoritas penduduk bekerja dibidang kerajinan tangan termasuk 7 responden dalam penelitian ini. Menurut Swasono (2005) bahwa pekerjaan perempuan Indonesia mencapai $35,37 \%$ dari 100 juta angkatan kerja. ${ }^{2} \mathrm{Hal}$ tersebut karena meningkatnya kebutuhan hidup dan pemahaman kaum wanita tentang aktualisasi diri. ${ }^{3}$ Kerja dapat memberikan kesibukan jauh lebih besar dibandingkan dengan ibu rumah tangga. Selain itu pekerjaan juga erat kaitannya dalam pembentukan perilaku.

Menurut Notoatmodjo (2003) bahwa manusia mempelajari kelakuan ari orang lain ilingkungan sosialnya. ${ }^{4}$ Ibu yang bekerja sebagai pengrajin empunyai lingkungan sosial yang lebih luas dibandingkan dengan ibu yanghanya sebagai ibu rumah tangga. Pergaulan sosial yang luas tidak hanyaberdampak pada tingkat perolehan informasi tetapi juga dalam halmenirukecenderungan(trend) yang berkembang dalam lingkungan sosialnya. Misalnya meniru teman kerja atau lingkungan tempat bekerja yangmemberikan susu botol pada anaknya sehingga ibu tidak memberikan ASI ksklusif.
Ibu menyusui di BPS Umu Hani sebagian besar menyusui bayinysecara eksklusif yaitu sebanyak 30 orang $(68,2 \%)$. Sedangkan 14 orang $(31,8 \%)$ lainnya tidak memberikan ASI secara eksklusif. Pemberian ASleksklusif adalah ibu yang hanya memberikan ASI saja sampai usia 6 bulantanpa tambahan apapun kecuali obat dan air putih (satu sendok teh).Pemberian ASI eksklusif merupakan salah satu perilaku kesehatan setelahmelahirkan (pasca melahirkan).

Menurut Soi (2006) ASI sebagai makanan terbaik bagi bayi pada awalkehidupan untuk dapat tumbuh dan berkembang secara optimal,bagi bayi ASI juga mengandung zat-zat imunologis yang bermanfaat bagi pencegahaninfeksi terutama diare dan infeksi saluran pernafasan akut,bermanfaat sebagainutrisi, daya tahan tubuh bayi dan meningkatkan kecerdasan. ${ }^{5} \mathrm{Hasilpenelitian}$ ini sesuai dengan hasil penelitian yang dilakukan oleh Sugiarti(2007) yang menyatakan bahwa faktor pekerjaan ibu berpengaruh terhadappemberian ASI eksklusif sesuai dengan kondisi pekerjaannya. ${ }^{6}$

Hasilpenelitianini juga sejalan dengan penelitian yang dilakukan oleh Rahayuningsih (2006) ang menyatakan bahwa ada hubungan antara pekerjaan dengan pemberian ASI eksklusif pada ibu yang mempunyai bayi usia 6 bulan di wilayah kerja Puskesmas Mergangsan. ${ }^{7}$

Hasil penelitian ini juga sejalan dengan penelitian yang dilakukan oleh Susilawati (2008) yang menyatakan bahwa ada hubungan antara status pekerjaan ibu dengan pemberian ASI eksklusif padaibu yang mempunyai bayi usia 6-12 bulan di Desa Srihardono Pundong Bantul. ${ }^{3}$ Selain itu, hasil penelitian ini juga sesuai dengan pendapat Soetjiningsih(1997) yang menyatakan bahwa pekerjaan merupakan salah satu faktor yangdapat mempengaruhi ibu dalam pemberian ASI eksklusif. ${ }^{8}$

\section{Simpulan dan Saran}

\section{Simpulan}

Sebanyak $84,1 \%$ ibu menyusui di BPS Umu Hani Bantul menjadi ibu rumah tangga dan 15,9\% ibu menyusui di BPS Umu Hani Bantul bekerja diluar rumah. Sebanyak $68,2 \%$ ibu menyusui di BPS Umu Hani Bantul memberikan ASI secara eksklusif. Ada perbedaan yang signifikan proporsi pemberian ASI ekslusif pada ibu rumah tangga dan ibu yang bekerja diluar rumah di BPS Umu Hani Bantul.

\section{Saran}

Berdasarkan hasil penelitian ini, BPS Umu Hani hendaknya memberikan penyuluhan kepada ibu 
yang menyusui dan memeriksakan diri ke BPS Umu Hani untuk memberikan ASI secara eksklusif kepada bayinya untuk meningkatkan cakupan ASI eksklusif di BPS Umu HaniBantul 2011. Pada ibu yang bekerja hendaknya dapat memberikan ASI kepadabayinya dengan cara langsung memberikan ASI sebelum dan setelah bekerja dan menyiapkan ASI.

\section{Daftar Pustaka}

1. Dinkes DIY.2009.Jumlah bayi yang diberi ASI eksklusif Provinsi Daerah Istimewa Yogyakarta tahun 2009. Yogyakarta:Dinkes.

2. Swasono,M.H. (2005)."Hak Menyusui bagi Tenaga Kerja Perempuan" dalam http://umihaafizh. multiply.com/journal/item/13. Jumat. 11 Maret 2011. Pukul 16.09 WIB.

3. Susilawati, Dian. (2008).Hubungan antara status pekerjaan dengan pemberian ASI eksklusif pada ibu yang mempunyai bayi 6 - 12 bulan di desa Sri Hardono Pundong,Bantul.Poltekkes : Yogyakarta.

4. Notoatmodjo, S . (2003). Pendidikan dan Perilaku Kesehatan. Jakarta : Rineka Cipta.

5. Soi, Beatrix. "Pengaruh status gizi ibu menyusui terhadap eksklusivitas ASI dan pertumbuhan bayi di RSUD Prof.Dr. WZ Johannes Kupang- NTT". Jurnal Gizi Klinik Indonesia, 2006.2(3):101-107.

6. Sugiarti, Meli."Persepsi ibu tentang faktorfaktor yang mempengaruhi lamanya ibu dalam memberikan air susu ibu". Jurnal IImu Keperawatan.2007:02(2):83-88.

7. Rahayuningsih, Lina. (2006). Hubungan antara pekerjaan dengan pemberian ASI eksklusif pada ibu yang mempunyai bayi usia 9 bulan di wilayah kerja Puskesmas Mergangsan tahun 2006. Poltekkes : Yogyakarta.

8. Soetjiningsih. 1997. ASI: Petunjuk untuk tenaga kesehatan. Jakarta: EGC. 